\title{
ESTÁGIO SUPERVISIONADO E RESIDÊNCIA PEDAGÓGICA: POSSIBILIDADES PARA FORMAÇÃO DOCENTE CRÍTICA
}

\author{
PRACTICAS SUPERVISADAS Y RESIDENCIA PEDAGÓGICA: POSIBILIDADES DE \\ UNA FORMACIÓN CRÍTICA PARA LOS MAESTROS
}

\author{
SUPERVISED INTERNSHIP AND PEDAGOGICAL PROBATION: POSSIBILITIES \\ FOR CRITICAL TEACHER FORMATION
}

\author{
Alessandra de Oliveira MACIEL ${ }^{1}$ \\ Ana Ignez Belém Lima NUNES ${ }^{2}$ \\ José Airton de Freitas PONTES JUNIOR ${ }^{3}$
}

RESUMO: Tendo como referências as políticas de direitos humanos e direitos fundamentais, a Constituição de 1988 e a LDB de 1996, a discussão da Política Nacional de Formação de Professores visa propor caminhos para superar a perspectiva reducionista de formação centrada nos processos de ensino e aprendizagem para ocupar-se também das relações humanas. $\mathrm{O}$ estudo teve como objetivo analisar o papel do Estágio Curricular Supervisionado (ECS) e da Residência Pedagógica (RP) como possíveis espaços de formação docente crítico-reflexiva. Em um estudo de caso de abordagem qualitativa, aplicamos um questionário a $56,8 \%$ dos coordenadores de ECS de uma universidade pública cearense, e na segunda etapa, realizamos entrevista semiestruturada com 04 desses coordenadores que assumem o ECS e a RP. As análises revelaram que as ações formativas da RP têm favorecido maior inserção docente e discente de forma crítica e reflexiva em relação às práticas acadêmicas e escolas participantes.

PALAVRAS-CHAVE: Estágio supervisionado. Residência pedagógica. Formação docente.

RESUMEN: El artículo está basado en las politicas de derechos humanos y derechos fundamentales, la Constitución del año 1988 y la LDB del año 1996, para discutir la Política Nacional para la Formación de Docentes en Brasil. Así que presenta reflexiones para superar la perspectiva reduccionista de la formación centrada tan sólo en los procesos de enseñanza y aprendizaje para abordar también las relaciones humanas. El estudio tuvo como objetivo analizar el rol de la Práctica Curricular Supervisada (PCS) y de la Residencia Pedagógica (RP) como espacios posibles para la formación docente crítico y reflexiva. En un estudio de caso cualitativo, pasamos un cuestionario al 56,8\% de los coordinadores de ECS en una universidad pública. En la siguiente etapa, hicimos una entrevista semiestructurada con 04 de estos coordinadores que asumen el ECS y el PR. Los análisis revelaron que las acciones de

${ }^{1}$ Universidade Estadual do Ceará (UECE), Fortaleza - CE - Brasil. Doutoranda no Programa de Pós-Graduação em Educação. ORCID: https://orcid.org/0000-0003-1072-1074. E-mail:alessandragomaciel@gmail.com

${ }^{2}$ Universidade Estadual do Ceará (UECE), Fortaleza - CE - Brasil. Professora no Programa de Pós-Graduação em Educação. Doutorado em Ciências da Educação (USC) - Espanha. ORCID: https://orcid.org/0000-0001-61069229. E-mail: anaignezbelem@gmail.com

${ }^{3}$ Universidade Estadual do Ceará (UECE), Fortaleza - CE - Brasil. Professor no Programa de Pós-Graduação em Educação. Doutorado em Educação (UFC). ORCID: https://orcid.org/0000-0003-2045-2461. E-mail: jose.airton@uece.br

RIAEE - Revista Ibero-Americana de Estudos em Educação, Araraquara, v. 15, n. esp. 3, p. 2223-2239, nov. 2020. e-ISSN: 1982-5587 DOI: https://doi.org/10.21723/riaee.v15iesp3.14428 
formación de la RP han favorecido una inserción de docentes y estudiantes en un contexto crítico y que refleja las prácticas académicas y las escuelas desarrolladas.

PALABRAS CLAVE: Prácticas supervisadas. Residencia pedagógica. Formación de profesores.

ABSTRACT: Based on human rights and fundamental rights policies, the Constitution of 1988 and the LDB of 1996, the National Teacher Formation Policy discussion aims to propose ways to include human relations on focus too, besides overcoming the reductionist perspective of training centered on teaching and learning processes. The study aimed to analyze the Supervised Curricular Internship (SCI) and Pedagogical Probation (PP) roles as possible spaces for critical-reflective teacher training. In a case study with a qualitative approach, we applied a questionnaire to $56.8 \%$ of the SCI coordinators of a public university in Ceará, and in the second stage, we conducted a semi-structured interview with 04 of these coordinators who work at both the SCI and the PP. The analyses revealed that the PP formative actions have favored greater teacher and student insertion in a critical and reflective way in relation to the academic practices and participating schools.

KEYWORDS: Supervised internship. Pedagogical probation. Teacher formation.

\section{Introdução}

A presente escrita parte do pressuposto que a formação não se restringe a um só momento. Trata-se de um movimento coletivo, integrado ao processo de transformação, inovação e desenvolvimento educacional e social.

Desse modo, compete às licenciaturas a ação de formar o futuro professor para o exercício da docência, o que se demonstra ser uma tarefa complexa. Tal complexidade demanda a competência de recontextualizar a instituição formadora, bem como de reconfigurar os conhecimentos necessários à formação docente. A formação adota uma posição de “[...] emancipamento, vinculada à história de vida dos sujeitos em permanente processo de formação, que proporciona o desenvolvimento profissional” (VEIGA, 2014, p. 331). Trata-se de uma formação que compreenda a docência como prática social, arraigada no científico-pedagógico, numa perspectiva crítico-reflexiva.

Nesse sentido, Gatti (2010) se reporta ao envolvimento das instituições de ensino superior na qualidade da formação inicial dos professores. Essas instituições precisam perceber a complexidade da formação e da atuação desse profissional, pois formar professores tem ultrapassado a esfera do governo e alcançado a sociedade, pois passaram a perceber as mudanças ao longo dos tempos e a necessidade da educação em acompanhar essas transformações.

RIAEE - Revista Ibero-Americana de Estudos em Educação, Araraquara, v. 15, n. esp. 3, p. 2223-2239, nov. 2020. e-ISSN: 1982-5587 DOI: https://doi.org/10.21723/riaee.v15iesp3.14428 
Ghedin, Almeida e Leite (2008) alegam que os programas dos cursos de licenciatura e suas diversas disciplinas estão, de uma forma geral, estruturados curricularmente, no entanto, desconectadas da prática e da realidade existentes no âmbito do sistema escolar e contexto social. Nessa perspectiva, destacamos o estágio supervisionado como um componente curricular obrigatório nos cursos de formação de professores por entendermos que se propõe a firmar um diálogo entre a teoria veiculada ao curso e disciplinas com a prática constituída nas escolas, lócus do estágio.

O estágio supervisionado é compreendido como um campo de aprendizagem do saberfazer docente e de constituição da identidade profissional. Deve reconhecer a capacidade do professor na elaboração de conhecimento, na tomada de decisões e na participar da gestão escolar como ações ontologicamente inerentes ao movimento de constituição da própria humanidade (GHEDIN; OLIVEIRA; ALMEIDA, 2015).

Dessa forma, o estágio se torna o lócus onde "a identidade profissional do aluno é gerada, construída e referida" (BURIOLLA, 1999, p. 13) no entrelaçamento de percursos individuais e coletivos, sob o prisma da reflexão crítica, oportunizando a articulação entre a teoria e a prática. Abordar o ECS como o espaço para essa relação é compreendê-lo como momento de reflexão crítica sobre seu fazer pedagógico, de maneira a articular e redimensionar suas ações, assimilando o ensino em sua multiplicidade, buscando, constantemente, reflexionar sua ação profissional no sentido de uma posição crítica ante aos saberes e à realidade social.

Pactuamos com Pimenta e Lima (2017) quando afirmam que o ECS oportuniza aos estudantes novas possibilidades de aprender aspectos acerca da profissão docente, igualmente para os professores formadores, encorajando-os a revisitar suas concepções e práticas. Ressaltamos que esse componente curricular deve conectar as demais disciplinas que envolvem a proposta curricular do curso, posto que incorporam conhecimentos e saberes que serão requisitados durante os períodos de prática e no decorrer do seu desenvolvimento profissional.

Dessarte, a importância do ECS para o currículo da formação inicial de professores é inegável. Entretanto, essa compreensão não decorre do acaso, é gerada em decorrência de estudos e pesquisas acerca da função formadora desse componente curricular e que, como consequência, vem motivando diretrizes e normativas para os cursos de formação docente.

Nessa perspectiva, sinalizamos que a Lei de Diretrizes e Bases (LDB), lei nº. 9394/96, que estabelece as "diretrizes e bases da educação nacional", em seu artigo 61 trata da "formação de profissionais da educação" e deixa claro a articulação da teoria e prática como aspecto fundante na formação de professores "I - A associação entre teorias e práticas, inclusive mediante a capacitação em serviço [...]”".

RIAEE - Revista Ibero-Americana de Estudos em Educação, Araraquara, v. 15, n. esp. 3, p. 2223-2239, nov. 2020. e-ISSN: 1982-5587 DOI: https://doi.org/10.21723/riaee.v15iesp3.14428 
A aprovação da LDB instituiu-se como marco das políticas educacionais, desencadeando regulamentações, pareceres e resoluções pelo Conselho Nacional de Educação nos últimos anos. Dentro desse percurso histórico, destacamos a Resolução no ${ }^{\circ}$ 2/2019, que define as Diretrizes Curriculares Nacionais para a Formação Inicial de Professores para a Educação Básica e institui a Base Nacional Comum para a Formação Inicial de Professores da Educação Básica (BNC-Formação).

Nessa resolução a articulação entre teoria e prática é citada em dois momentos no texto: como fundamento da política de formação docente e na organização curricular dos cursos superiores para formação docente. No entanto, ao mencionar o estágio curricular há uma certa predominância do aspecto da prática na estruturação e sistematização deste componente.

Nessa vertente, a Coordenação de Aperfeiçoamento de Pessoal de Nível Superior (CAPES), fundação vinculada ao Ministério da Educação, lança por meio da Portaria GAB nº. 38/2018 o Programa Residência Pedagógica (RP). Entre os objetivos desse programa está a melhoria da qualidade dos cursos de licenciatura, através de experiências docentes que favoreçam a relação teoria e prática (FERREIRA; SIQUEIRA, 2020).

Diante desse cenário legislativo favorável, nos inquieta conhecer como o ECS e a RP evidenciam a articulação teoria e prática, eixos indissociáveis no processo de formação docente, numa perspectiva reflexiva.

Desse modo, a propositura desta investigação tem interesse em contribuir para a ampliação desse campo investigativo e para a discussão de políticas que envolvam a formação de professores, em especial o estágio curricular como espaço propício para reflexão crítica ante a realidade social e educacional que o campo lhe apresenta.

\section{Estágio curricular supervisionado, Residência pedagógica e Formação docente: aspectos teóricos e conceituais}

Entendemos que educação está relacionada aos conhecimentos, ideias, conceitos, valores, atitudes, hábitos, símbolos, dentre outros. Estes aspectos, necessários à formação da humanidade em cada indivíduo, é produzido intencionalmente, através de relações pedagógicas entre os seus pares (SAVIANI, 2015).

Desse modo, consideramos que há uma especificidade na ação docente (ciência da educação) que se difere das demais ciências, pois se preocupa com a identificação dos elementos necessários à constituição do conhecimento em cada ser humano e à busca de estratégias adequadas para alcançar esse objetivo.

RIAEE - Revista Ibero-Americana de Estudos em Educação, Araraquara, v. 15, n. esp. 3, p. 2223-2239, nov. 2020. e-ISSN: 1982-5587 DOI: https://doi.org/10.21723/riaee.v15iesp3.14428 
Corroboramos a compreensão de Tardif(2014) de que a formação docente presume uma continuidade que precede a universidade, resgata elementos da formação escolar, passa pela formação inicial, fase esta que legitima o ingresso na profissão, e prossegue durante sua atuação profissional.

De acordo com Garcia (1999), a formação de professores se constitui pelos processos de formação inicial e continuada, onde adquirem ou ressignificam conhecimentos, habilidades e atitudes essenciais ao exercício da atividade docente. Nessa lógica, corroboramos a imagem da formação de professores associada às distintas maneiras de continuar a expandir os seus conhecimentos, habilidade e atitudes, refletindo sobre sua prática com o objetivo de indicar as mudanças necessárias.

Aliançado a essa compreensão, Imbernón (2011) sustenta que a formação deve desenvolver nos professores conhecimentos, habilidades e atitudes que lhes deem condições de refletir sobre a própria prática docente, ou seja, deve proporcionar “[...] uma prática reflexiva competente" (p. 18), posicionamento também assumido por nós.

Nesse sentido, numa perspectiva crítica, compreendemos a formação de professores como processo de desenvolvimento profissional com respaldo teórico e reflexão crítica sobre sua prática, analisando determinantes sociais e históricos de sua atuação e de sua profissão e reconhecendo a dimensão social, política e transformadora de sua ação.

Entendemos o espaço da formação de professores propício para essa reflexão que busca um sentido maior para as práticas desenvolvidas pelos docentes. No entanto, o que se tem percebido, segundo Tardif (2014), é uma prática reprodutivista, em que os estudantes frequentam disciplinas com conteúdo proposicional e que serão aplicados no período do estágio. Ou seja, uma formação que segue um modelo aplicacionista.

Pimenta (2012) também destaca o fato de que a formação de professores é pouco eficiente por não considerar essas atribuições em seus contextos, não possibilitando a articulação e tradução de novos saberes em novas práticas. Com relação às licenciaturas, essa autora acentua que se espera que sejam desenvolvidos nos estudantes conhecimentos, habilidades e atitudes que lhes possibilitem constituir seu saber fazer, seus saberes docentes, partindo das necessidades e desafios que o ensino, como prática social, os coloca cotidianamente.

A formação de professores tem ocupado posição de destaque nas discussões nos últimos anos no sentido da necessidade de uma renovação educativa, o que exige reflexão e envolvimento responsável com a qualidade da formação desses profissionais. Estabelecer o 
perfil do profissional que se pretende formar é fundamental, tendo em vista que a proposta curricular dos cursos de formação docente deve ser sistematizada numa perspectiva crítica.

Reconhecemos que a formação inicial não tem a pretensão de dar conta da complexidade que envolve a prática docente, mas terá que oportunizar ao estudante a compreensão da importância da reflexão e da criticidade acerca das situações que envolvem a profissão docente para que busque seu crescimento profissional. Assim, o futuro professor se tornará consciente de que "[...] faz parte de sua tarefa docente não apenas ensinar os conteúdos, mas também ensinar a pensar [...]" (FREIRE, 2019, p. 27).

Acerca desse fazer pensar, recorremos à concepção de Carretero (2019, p. 925), quando afirma que se trata de "um gesto que significa pôr em jogo experiências que aportam novos olhares e que são oportunas na situação que se gera [...]”. Portanto, essa indicação supera a perspectiva de problematização da prática, exige introduzir elementos que contribuam para reflexão a partir do que ocorreu na situação vivenciada, ampliando os recursos profissionais.

Desta feita, concordamos em pensar a formação do professor como um processo que se estabelece também pela experiência prática numa perspectiva crítico-reflexiva, tendo em vista as necessidades e desafios que a profissão evidencia. Para tal, essa formação precisa favorecer ao futuro professor a articulação reflexiva entre os conhecimentos e direcionada ao fomento da autonomia tanto do docente quanto do aluno (COSTA; SANTOS; MARTINS, 2020). E é nesse processo que destacamos o período do estágio curricular supervisionado e de programas, como o de residência pedagógica, que podem oportunizar essa experiência prático-reflexiva.

Os momentos de prática docente tais como os vivenciados no ECS e na RP são considerados espaços frutíferos para essa ação reflexiva, para articulação teoria e prática. Nessa atmosfera/ambiente, evidenciam-se apreensões, dúvidas, descobrimentos, conquistas, revelações e dubiedades em relação a profissão. É percebido a complexidade que envolve o cenário profissional e inicia-se o esforço na direção das soluções num fluxo contínuo de reflexão-ação-reflexão (SHÖN, 2000).

Nessas circunstâncias, os estudantes adentram a realidade dos espaços onde o ensino se manifesta, realizam observações e partilham os contextos e situações vivenciadas. Essas ações realizadas de forma reflexiva, favorecem a constituição de saberes e de saber-fazer nos futuros professores. Por conseguinte, refere-se a um aspecto estrutural da formação que pode possibilitar a experimentação de processos que são gerados no ambiente da sala de aula. Nesse contexto, o professor-supervisor tem a oportunidade de contribuir com a formação desse futuro professor, bem como também aprender, numa perspectiva de coformação, em que ambos estão se desenvolvendo profissionalmente (SILVÉRIO, 2014; CARVALHO; SOUZA NETO, 2019). 
É nessa relação com os estudantes em sala de aula que o futuro professor, por intermédio das vivências, desenvolverá habilidades referentes a profissão, aspecto que os estágios agregam no processo formativo inicial do docente (FISTAROL; FISCHER; BAILER, 2018).

Partindo dessas concepções, definimos o percurso metodológico desenvolvido na investigação, que estavam diretamente relacionados com o objeto de pesquisa, gerando as condições necessárias para o alcance dos objetivos estabelecidos no início desta escritura.

\section{Percurso metodológico}

Nosso estudo satisfaz à abordagem de investigação qualitativa numa perspectiva teórica interpretativa, uma vez que privilegia a compreensão do fenômeno a ser estudado. Esse paradigma interpretativo na pesquisa intenta compreender e interpretar a realidade e os seus significados; tem como intenção de pesquisa "Compreender e interpretar a realidade, os significados das pessoas, percepções, intenções, ações” (ESTEBAN, 2010, p. 34); possui características de natureza holística, dinâmica e simbólica dos processos socioculturais; percebe o contexto como fator constitutivo dos significados sociais; reconhece a ação humana como objeto de pesquisa.

Dando seguimento, escolhemos o estudo de caso como método para essa investigação, referenciado o que dizem Lüdke e André (1986), afirmando que o ambiente natural é a fonte direta de dados, onde são encontrados na realidade investigada. O problema estudado é observado por via de suas manifestações no cotidiano, e a perspectiva dos participantes quanto às questões analisadas é levada em consideração.

Os escritos de Yin (2010, p. 32) ensinam que o Estudo de Caso é o método mais adequado à nossa abordagem de investigação, pois permite a investigação de um fenômeno, preservando os significados dos eventos na vida real, e de teor descritivo e explanatório.

Desse modo, elegemos como lócus para esse estudo a Universidade Estadual do Ceará (UECE), por se tratar de uma instituição de ensino superior responsável por formar vários profissionais na área de educação no Estado do Ceará.

A IES pesquisada é uma instituição pública estadual, criada de março de 1975, do Conselho Diretor da Fundação Educacional do Estado do Ceará (FUNEDUCE). Concebida com o objetivo de atender às necessidades do desenvolvimento científico e tecnológico do Estado do Ceará, a UECE passou a atuar em outros municípios do Estado, e a partir daí, estruturou-se em rede multicampi, com faculdades em outros municípios do Estado, além de Fortaleza (UECE, 2017).

RIAEE - Revista Ibero-Americana de Estudos em Educação, Araraquara, v. 15, n. esp. 3, p. 2223-2239, nov. 2020. e-ISSN: 1982-5587 
Por priorizar os cursos voltados para a formação de professores, esta Universidade acumula experiências e transforma o seu perfil curricular em razão da melhoria da formação profissional de seus alunos e, consequentemente, da elevação da qualidade de vida da sociedade cearense. Deste modo, o ensino tem se constituído atividade por excelência da UECE, desde sua origem, principalmente o de graduação, com a preocupação pela sua qualidade, objetivando a formação de profissionais capacitados para acolher as demandas sociais e profissionais do Estado e da Região.

No período em que a UECE foi criada, início dos anos de 1970, ocorreu anos antes a promulgação da LDB de $\mathrm{N}^{\mathrm{o}} 5.692 / 71$, que firmava as diretrizes e bases para o ensino de $1^{\circ}$ e $2^{\circ}$ graus. Nesse documento, foi possível identificar, mais especificamente no capítulo V, Art. 29, que a formação de professores para o ensino deveria ser realizada em níveis de progressão, considerando as diferenças culturais de cada região do País, e com indicação que acolhesse os objetivos específicos de cada grau, as particularidades das disciplinas, áreas de estudo ou atividades e fases de desenvolvimento dos estudantes.

Durante os anos de 1980, a UECE começou um processo de expansão, quando cursos de extensão foram criados, outros cursos de graduação foram acrescentados e as primeiras experiências com cursos de pós-graduação lato sensu foram despontando, sempre mantendo a missão de produzir e disseminar conhecimentos e formar profissionais para promover o desenvolvimento sustentável e a qualidade de vida da região.

Por ter esta característica de descentralização, mas mantendo o mesmo propósito, é que se considera esta Universidade como multicampi, pois atende os cearenses que residem em diversas regiões do Estado. Seus cursos estão distribuídos em cinco centros e sete faculdades, órgãos estes responsáveis por “[...] supervisionar, mediar, integrar e assessorar as atividades de ensino, pesquisa e extensão, em campos de conhecimentos específicos, delimitados administrativamente" (UECE, 2017, p.18).

A UECE está representada em três campi na capital e oito no interior do Estado. No entanto, apenas oito desses campi ofertam cursos de licenciatura, expostos no quadro 1.

Quadro 1 - Cursos de licenciatura ofertados pela UECE por Campus

\begin{tabular}{|c|l|l|}
\hline & \multicolumn{1}{|c|}{ CAMPUS } & \multicolumn{1}{c|}{ CURSO } \\
\hline $\mathbf{1}$ & Crateús & Ciências Biológicas, História, Pedagogia, Química. \\
\hline $\mathbf{2}$ & Fortaleza - Itaperi & $\begin{array}{l}\text { Ciências Biológicas, Ciências Sociais, Educação Física, Física, Geografia, } \\
\text { História, Matemática, Música, Pedagogia, Química. }\end{array}$ \\
\hline $\mathbf{3}$ & Fortaleza - Fátima & Filosofia, Letras Espanhol, Letras Francês, Letras Inglês, Letras Português. \\
\hline $\mathbf{4}$ & Iguatu & $\begin{array}{l}\text { Ciências Biológicas, Física, Letras Inglês, Letras Português e Literatura, } \\
\text { Matemática, Pedagogia. }\end{array}$ \\
\hline $\mathbf{5}$ & Itapipoca & Ciências Biológicas, Ciências Sociais, Pedagogia, Química. \\
\hline
\end{tabular}

RIAEE - Revista Ibero-Americana de Estudos em Educação, Araraquara, v. 15, n. esp. 3, p. 2223-2239, nov. 2020. e-ISSN: $1982-5587$ DOI: https://doi.org/10.21723/riaee.v15iesp3.14428 


\begin{tabular}{|c|l|l|}
\hline $\mathbf{6}$ & Limoeiro do Norte & $\begin{array}{l}\text { Ciências Biológicas, Física, Geografia, História, Letras Inglês, Letras Português, } \\
\text { Matemática, Pedagogia, Química. }\end{array}$ \\
\hline $\mathbf{7}$ & Quixadá & $\begin{array}{l}\text { Ciências Biológicas, Física, História, Letras Inglês, Letras Português, } \\
\text { Matemática, Pedagogia, Química. }\end{array}$ \\
\hline $\mathbf{8}$ & Tauá & Ciências Biológicas, Pedagogia, Química. \\
\hline
\end{tabular}

Fonte: Elaborado pelos autores

Desta feita, a pesquisa de campo foi realizada em duas etapas: (1) aplicação de questionário com todos os professores de ECS nas licenciaturas da IES investigada; (2) entrevista com quatro professores que atuam tanto no ECS quanto na RP. Na primeira etapa (1) foram contabilizados 44 professores coordenadores de ECS nos cursos de licenciatura da UECE, capital e interior do estado. Desse quantitativo, $56,8 \%$ responderam ao questionário enviado acerca do trabalho desenvolvido no ECS em cada curso. Tal instrumento foi elaborado no Google Forms e enviado por e-mail, assim como as informações sobre a proposição da pesquisa.

Acerca desse instrumento, Dalberio e Dalberio (2009) afirmam que existe a produção de respostas diretas e explícitas, favorecendo a consecução dos dados com precisão. Em relação a esse estudo, elegemos um questionário de perguntas abertas que nos possibilitasse singularizar o posicionamento de cada professor participante. No quadro 2 apresentamos os quantitativos de coordenadores/cursos, o campus/cidade onde é ofertado, e os respectivos percentuais de participação.

Quadro 2 - Percentuais de participação por campus/cidade da UECE

\begin{tabular}{|c|c|c|c|c|}
\hline & CAMPUS & $\mathrm{N}^{\mathrm{o}}$ de Cursos & $\begin{array}{l}\mathrm{N}^{0} \text { de Curso } \\
\text { participantes }\end{array}$ & $\%$ \\
\hline 1 & Crateús & 4 & 2 & 50,0 \\
\hline 2 & Fortaleza & 12 & 7 & 58,3 \\
\hline 3 & Iguatu & 6 & 3 & 50,0 \\
\hline 4 & Itapipoca & 4 & 3 & 75,0 \\
\hline 5 & Limoeiro do Norte & 8 & 6 & 75,0 \\
\hline 6 & Quixadá & 7 & 3 & 42,8 \\
\hline \multirow[t]{2}{*}{7} & Tauá & 3 & 1 & 33,3 \\
\hline & Total & 44 & 25 & 56,8 \\
\hline
\end{tabular}

Fonte: Elaborado pelos autores

$\mathrm{Na}$ análise das respostas dos questionários dessa primeira etapa, encontramos alguns dados que despertaram nossa atenção: (1) frequência com que o Programa Residência Pedagógica foi citado como aspecto positivo na formação inicial docente e para formação continuada do professor da escola campo; (2) a dificuldade no acompanhamento e observação aos estudantes na escola campo de estágio; (3) ausência de uma parceria institucionalizada entre 
universidade e redes de ensino para o desenvolvimento do ECS e; (4) pouco envolvimento do professor supervisor da escola com os estudantes do ECS.

Tais achados nos direcionaram para a segunda etapa, para análise do papel do Estágio Curricular Supervisionado (ECS) e da Residência Pedagógica (RP) como possíveis espaços de formação docente crítico-reflexiva. Reconhecemos nesse estudo a possibilidade de discutir a formação de professores como um campo contínuo de reflexão da prática docente (FREIRE, 2019).

Desse modo, selecionamos sete cursos de licenciatura cujos professores de ECS também assumiram a RP. São eles: Física, em Fortaleza; Ciências Biológicas, em Limoeiro do Norte, Iguatu e Crateús; Pedagogia, em Itapipoca e Iguatu; Educação Física, em Fortaleza. Na sequência, entramos em contato com os professores participantes com o objetivo de agendar as entrevistas, que foram realizadas via Google Meet, gravadas de forma individual.

Ressaltamos que apenas quatro, dos sete professores coordenadores, nos retornaram marcando suas entrevistas. Como não obtivemos resposta dos demais, seguimos com a investigação com os professores que aceitaram participar da pesquisa.

Oportunamente esclarecemos que, respeitando o aspecto ético, optamos por resguardar a identidade dos participantes. Desse modo, recorremos a codificação "P” para os professores participantes, seguido da numeração 1 a 4 . O quadro 03 traz os dados gerais desses professores participantes.

Quadro 3 - Perfil dos professores participantes da pesquisa

\begin{tabular}{|c|c|c|c|c|c|c|}
\hline & $\begin{array}{l}\text { Formação em nível } \\
\text { de Graduação }\end{array}$ & $\begin{array}{c}\text { Maior } \\
\text { Titulação }\end{array}$ & Vínculo & $\begin{array}{c}\text { Tempo de } \\
\text { magistério no } \\
\text { Ensino } \\
\text { Superior } \\
\end{array}$ & $\begin{array}{l}\text { Tempo de } \\
\text { magistério } \\
\text { no ECS }\end{array}$ & $\begin{array}{c}\text { Tempo na } \\
\text { Coordenação } \\
\text { da RP }\end{array}$ \\
\hline P1 & $\begin{array}{l}\text { Licenciatura em } \\
\text { Educação física }\end{array}$ & $\begin{array}{l}\text { Mestrado em } \\
\text { Ciências } \\
\text { Fisiológicas }\end{array}$ & $\begin{array}{l}\text { Professor } \\
\text { efetivo }\end{array}$ & 8 anos & 4 anos & 18 meses \\
\hline P2 & $\begin{array}{c}\text { Serviço social e } \\
\text { Pedagogia }\end{array}$ & $\begin{array}{c}\text { Doutorado em } \\
\text { Educação }\end{array}$ & $\begin{array}{c}\text { Professor } \\
\text { efetivo }\end{array}$ & + de 10 anos & 5 anos & $\begin{array}{l}\text { Iniciará } \\
\text { em } 2020\end{array}$ \\
\hline P3 & $\begin{array}{l}\text { Licenciatura em } \\
\text { Matemática e } \\
\text { Ciências (com } \\
\text { habilitação em } \\
\text { Física) }\end{array}$ & $\begin{array}{l}\text { Doutorado em } \\
\text { Educação }\end{array}$ & $\begin{array}{l}\text { Professor } \\
\text { efetivo }\end{array}$ & 19 anos & 2 anos & 2 anos \\
\hline P4 & $\begin{array}{c}\text { Bacharelado e } \\
\text { Licenciatura em } \\
\text { Ciências biológicas }\end{array}$ & $\begin{array}{l}\text { Doutorado em } \\
\text { Bioquímica. }\end{array}$ & $\begin{array}{l}\text { Professor } \\
\text { efetivo }\end{array}$ & 16 anos & 5 anos & $\begin{array}{l}\text { Iniciará } \\
\text { em } 2020\end{array}$ \\
\hline
\end{tabular}

Fonte: Elaborado pelos autores 
Em virtude do perfil demonstrado no quadro, observamos, primeiramente, o quesito gênero: três mulheres (Professoras 1, 2 e 3) e um homem. No que se refere à formação em nível de graduação, todos dos professores cursaram uma licenciatura e dois deles possuem as duas formações, licenciatura e bacharelado. Quanto à titulação, todos os docentes detêm a condição exigida pela legislação para o exercício da docência no ensino superior, ou seja, possuem mestrado ou doutorado. Percebemos que em relação ao vínculo com a Instituição de ensino superior todos os entrevistados foram enquadrados na categoria professor efetivo. Já em relação ao ensino superior, a experiência dos docentes é diversificada, variando entre 8 a 19 anos de magistério.

Seguimos a analisar as entrevistas com o intuito de perceber nas falas dos participantes, através da análise de conteúdo, elementos significativos, comuns e particulares a respeito da formação docente numa perspectiva crítica nos momentos de ECS e da RP. A classificação dos dados organizou-se das informações providas pelos docentes e dos aspectos revelados no referencial teórico. Essa análise foi feita fundamentada na subjetividade do investigador que se utiliza de categorias de análise e princípios teórico-metodológicos para sistematizar a interpretação e compreensão das informações coletadas (GOMES, 2009).

Apresentamos na próxima sessão as dimensões categorizadas a partir das entrevistas e percepções de cada participante, conforme sua realidade, da temática investigada.

\section{Resultados e discussões}

Como já antecipamos, os resultados que aqui apresentamos são provenientes das entrevistas realizadas com quatro professores coordenadores de ECS, em cursos de licenciatura da UECE. Utilizamos, para respaldar nossas análises, o mesmo referencial teórico já anunciado no início desse texto. Durante o processo de interpretação dos dados foi possível perceber aspectos positivos em relação ao ECS e RP embora, em algumas situações, não alcancem a completude de suas pretensões como espaço de formação docente crítica.

Conforme nossas escolhas metodológicas, organizamos os dados obtidos em categorias mais amplas, as quais chamamos de: (1) Dimensão documental: O PPC como promotor da perspectiva crítica na formação de professores; (2) Dimensão formativa: o que se espera de uma formação docente crítica? e (3) Dimensão da prática docente: constituir-se professor reflexivo. Tal organização teve com pretensão alocar as falas dos participantes de forma que pudéssemos compreender o papel do Estágio Curricular Supervisionado (ECS) e da Residência Pedagógica (RP) como possíveis espaços de formação docente crítico-reflexiva. 
$\mathrm{Na}$ apreciação dos dados, em relação à dimensão documental, identificamos que todos os cursos que fizeram parte dessa pesquisa estão em processo de atualização de seus PPCs. Os entrevistados confirmam a presença da perspectiva crítica nesse "novo" documento, embora o projeto pedagógico vigente nos cursos já apresente a importância de uma formação que articule a teoria e prática de forma indissociável. No entanto, em um dos cursos, ainda existem turmas de graduação que utilizam a matriz curricular de 1990, como afirma a professora P2

[...] até 2016 nós atuávamos numa matriz curricular de 1990 [...] e ainda atuamos pois ainda existem turmas utilizando esse PPC [...] nele as disciplinas de ECS não são tão claras. É prática, mas não tem esse nome de "estágio", são nomenclaturas antigas, fora do contexto de hoje como ensino do $1^{\circ}$ grau, do $2^{\circ}$ grau [...] após o concurso de 2016, os efetivos buscaram o PPC para compreender melhor e descobrimos que tinha o PPC em andamento (reformulação) desde de 2009, mas estava no conselho. Tentamos barrar pois começamos a revisá-lo e ainda estava separando a teoria e a prática [...] começamos a produção de um novo PPC [...] que estivesse mais atualizado nesse contexto de hoje.

É sabido que o planejamento das disciplinas se origina do PPC dos cursos, de suas concepções, objetivos e ementas da matriz curricular. Nesse sentido, foi possível perceber que os cursos aqui investigados tem buscado contemplar em seus projetos pedagógicos a perspectiva crítica na formação de professores e que os docentes participantes incorporam em suas práticas essa perspectiva, apesar do PPC em vigência, em alguns casos, necessitar de ajustes quanto à relação reflexiva entre a teoria e a prática.

A respeito da dimensão formativa todos concordam que tanto o estágio quanto a residência pedagógica potencializam a formação inicial dos futuros docentes. Entretanto, apresentam alguns elementos condicionantes. A professora P1 considera que quando o estudante tem um "bom" professor supervisor na escola, este

[...] consegue se desenvolver de forma potencial e fazer uma relação entre a teoria e prática. O preceptor precisa ter uma satisfação pessoal de conseguir fazer com que o aluno tenha sucesso ao realizar sua regência, seu planejamento, e ir conquistando e evoluindo nesse processo de formação [...].

Já as professoras P2 e P3, respectivamente, corroboram que dependerá muito do envolvimento do estudante, que ele entenda que "[...] está ali não só para cumprir uma parte prática do curso [...]”, mas é um espaço onde a teoria e prática se encontram e se articulam, e que esse saber é "[...] uma construção que o aluno precisa fazer [...]”.

Desse modo, observamos que na RP a figura do professor supervisor da escola campo se destaca na fala dos entrevistados, fato este não destacado em relação ao ECS. Esses dados

RIAEE - Revista Ibero-Americana de Estudos em Educação, Araraquara, v. 15, n. esp. 3, p. 2223-2239, nov. 2020. e-ISSN: 1982-5587 
nos fazem inferir sobre a possibilidade de potencializar a ação desse preceptor, no sentido de reconhecimento de sua ação formativa em relação ao estagiário, de sua atuação como coformador desse futuro professor. Os estudos de Milanesi (2012) e Barreto (2014) aponta que os professores supervisores da escola campo entrevistados demonstraram disposição para o diálogo entre docentes e estagiários, no sentido de ampliar as aprendizagens decorrentes dessa troca de experiência, por meio da qual todos os desenvolvem saberes acerca do processo educativo e do exercício profissional.

Ainda sobre o aspecto formativo, os professores participantes elegem alguns pontos acerca do ECS e da RP. Dentre os elementos que pontuaram destacamos as ações que se relacionam com uma proposta de formação docente crítica. Ressaltaram que ambos (ECS e RP) demonstram em suas propostas o compromisso com essa formação crítica e reflexiva. No entanto, consideram que a RP oferece ao estudante um tempo maior na instituição campo, onde pode conhecer, vivenciar e refletir sobre outros aspectos para além da regência em sala de aula. Nesse programa eles tem a oportunidade de diálogo com a gestão da escola, com os pais e contam, na maioria das vezes, com o acompanhamento de um professor supervisor comprometido com sua formação, nesse período de imersão no ambiente profissional do futuro professor.

Consideramos importante destacar que é unanime o reconhecimento da importância do ECS na formação docente, como afirma o professor P4 “[...] é praticamente um consenso de que o estágio é importantíssimo, é fundamental, ... devido a formação prática ofertada ao aluno e pela vivência na escola". Outro fator que os professores apontam é que o ECS alcança todos os estudantes das licenciaturas, ao passo que da RP só participam aqueles aprovados em seleção, conforme o número de vagas disponibilizadas no edital. Apesar desse programa ter muitos aspectos positivos, ainda se torna excludente em decorrência do quantitativo de licenciandos que tem a oportunidade de participar, situação pontuada como fragilidade dessa proposta formativa (P4).

Para os docentes investigados, a dimensão da prática docente como processo de constituição reflexiva, se revela quando reconhecem que as experiências do ECS e da RP contribuem para o desenvolvimento do pensamento crítico nos estudantes. Asseveram que a fala dos estudantes ao compartilharem suas vivências, discutirem e buscarem soluções em conjunto denota esse desenvolvimento, como bem relata a professora P1 "Você consegue visualizar na fala deles, consegue perceber o quanto que tudo que acontece ali é importante. O quanto eles identificam no campo e o quanto eles ouvindo o outro colega, desenvolvem a criticidade".

RIAEE - Revista Ibero-Americana de Estudos em Educação, Araraquara, v. 15, n. esp. 3, p. 2223-2239, nov. 2020. e-ISSN: 1982-5587 DOI: https://doi.org/10.21723/riaee.v15iesp3.14428 
O professor P4 integra nas atividades desenvolvidas no ECS elementos que estimulem a reflexão dos estudantes acerca da realidade da escola campo "oriento alguns itens no relatório final, onde tenham que fazer uma discussão reflexiva sobre alguns dos assuntos que eles vivenciaram na prática na escola, utilizando as referências bibliográficas que foram apresentadas na disciplina”. Já a professora P3 ressalta que na RP esses momentos de reflexão acontecem nos encontros de formação e que já constam no plano que será desenvolvido, ao contrário do ECS, que dependerá das escolhas do professor da disciplina em seu planejamento.

Embora admita que os estudantes desenvolvem o pensamento crítico durante o ECS e $\mathrm{RP}$, a professora P2 afirma que nem todos alcançam o progresso desejado. Ela sinalizou que estimula a realização das atividades de forma reflexiva, pois entende que "Não adianta só descrever a realidade, é preciso pensar sobre ela, como eu (estagiário) estou dentro dessa realidade para poder propor algo".

Nesse sentido, é fundamental a análise da própria prática, uma vez que as contradições presentes na realidade escolar nos impulsionam a buscar conhecimentos teóricos capazes de intermediar as reflexões para que a transformação dessa realidade possam ser geradas e apoiadas, também, numa visão crítica de mundo (MARSIGLIA; MARTINS, 2013).

\section{Considerações finais}

Diante das discussões postas anteriormente, consideramos que as duas experiências, ECS e RP, podem se constituir como espaços de formação docente crítica. As propostas descritas nos documentos que as regem já apontam a perspectiva crítica, embora em alguns casos precisem ser melhor definidas.

Ao reconhecermos esses espaços formativos, se faz necessário ultrapassar a esfera documental no sentido de ampliá-los e fortalecê-los. No entanto, a RP escapa à governabilidade da instituição de ensino superior, dificultando iniciativas de aprimoramento. Já o ECS favorece a ação interventiva da IES, no sentido de propor intentos que alcancem as expectativas formativas dos discentes, assim como os estimular a desenvolver um pensamento crítico e reflexivo antes mesmo de iniciarem sua carreira docente.

Percebemos que o fato do professor coordenador de ESC também estar envolvido na RP têm favorecido uma atuação profissional mais crítica e reflexiva em relação a sua prática docente. Tal movimento, acreditamos, reverbera nos discentes que estão sob seu comando, uma vez que serão propostas ações que fortaleçam a perspectiva crítica em sua formação inicial.

RIAEE - Revista Ibero-Americana de Estudos em Educação, Araraquara, v. 15, n. esp. 3, p. 2223-2239, nov. 2020. e-ISSN: 1982-5587 
Desse modo, os dois mecanismos de formação qualificam a formação dos futuros professores, favorecem a identificação de oportunidades de desenvolver uma ação docente onde teoria e prática caminham juntas e o pensamento crítico-reflexivo constitui-se elemento indispensável à profissão docente.

\section{REFERÊNCIAS}

BARRETO, E. S. O Estágio Supervisionado obrigatório na formação do professor de Ciências Biológicas da UFRPE: olhares de estagiários e orientadores. Orientadora: Maria Marly de Oliveira. 2014. 177 f. Dissertação (Mestrado em Ensino de Ciências) Universidade Federal Rural de Pernambuco, 2014.

BRASIL. Lei n. 5.692, de 11 de agosto de 1971. Fixa as Diretrizes e Bases para o Ensino de $1^{\circ}$ e $2^{\circ}$ graus, e dá outras providências. Diário Oficial da União: Seção 1, Brasília, DF, p. 6377, 12 ago. 1971. PLN 9/1971

BRASIL. Lei n. 9.394, de 20 de dezembro de 1996. Lei de Diretrizes e Bases da Educação Nacional. Diário Oficial da União: Seção 1, Brasília, DF, n. 248, p. 27833, 23 dez. 1996. PL 1258/1988

BRASIL. Ministério da Educação. Portaria GAB nº 38/2018, de 28 de fevereiro de 2018. Institui o Programa de Residência Pedagógica. Sistema Eletrônico de Informações/CAPES, Brasília, DF, 2018, 24 abr. 2018.

BRASIL. Resolução CNP/CP nº 02/2019. Define as Diretrizes Curriculares Nacionais para a Formação Inicial de Professores para a Educação Básica e institui a Base Nacional Comum para a Formação Inicial de Professores da Educação Básica (BNC-Formação). Diário Oficial da União nº 247, 23.12.2019, Seção 1, p.11. Diário Oficial da União: Brasília, DF, 2019.

BURIOLLA, M. A. O estágio supervisionado. 7. ed. São Paulo: Cortez, 2011.

CARRETERO, A. L. Ensinar o ofício do ensino: um ofício da alma. Revista IberoAmericana de Estudos em Educação, Araraquara, v. 14, n. 3, p. 917-927, jul./set. 2019. eISSN: 1982-5587. DOI: https://doi.org/10.21723/riaee.v14i3.11121

CARVALHO, T. F.; SOUZA NETO, S. Estágio supervisionado na Educação Física: a mobilização dos saberes docentes. Journal of Physical Education, v. 30, e3047, 2019. DOI: https://doi.org/10.4025/jphyseduc.v30i1.3047

COSTA, A. L. O.; SANTOS, A. R.; MARTINS, J. L. A formação docente: por uma prática educacional libertadora. Revista Ibero-Americana de Estudos em Educação, Araraquara, v. 15, n. 3, p. 1193-1204, jul./set. 2020. e-ISSN: 1982-5587. DOI:

https://doi.org/10.21723/riaee.v15i3.12511

DALBERIO, O.; DALBERIO, M. C. B. Metodologia científica: desafios e caminhos. São Paulo: Paulus, 2009. 
ESTEBAN, M. P. S. Pesquisa qualitativa em educação: fundamentos e tradições. Trad. Miguel Cabrera. Porto Alegre: AMGH, 2010.

FERREIRA, P. C. C.; SIQUEIRA, C. S. Residência Pedagógica: um instrumento enriquecedor no processo de formação docente. Revista Práticas de Linguagem, Juiz de Fora, v. 10, n. 1, p. 7-19, 2020. DOI: https://doi.org/10.34019/2236-7268.2020.v10.31448

FISTAROL, C. F. S.; FISCHER, A.; BAILER, C. O processo de estágio na formação docente de professores de língua inglesa: um olhar de licenciandas de um curso de Letras. Revista Ibero-Americana de Estudos em Educação, Araraquara, v. 13, n. 20, p. 623-637, abr./jun. 2018. e-ISSN: 1982-5587. DOI: https://doi.org/10.21723/riaee.v13.n2.2018.11333

FREIRE, P. Pedagogia da autonomia: saberes necessários à prática educativa. 60. ed. São Paulo: Paz e Terra, 2019.

GARCIA. C. M. Formação de professores: para uma mudança educativa. Porto: Porto, 1999.

GATTI, B. Formação de professores no Brasil: características e problemas. Educação e Sociedade, Campinas, SP, v. 31, n. 113, p. 1355-1379, dez. 2010. DOI:

https://doi.org/10.1590/S0101-73302010000400016

GHEDIN, E.; ALMEIDA, M. I.; LEITE, Y. U. F. Formação e professores: caminhos e descaminhos da prática. Brasília: Líber Livro, 2008.

GHEDIN, E.; OLIVEIRA, E. S.; ALMEIDA, W. A. Estágio com pesquisa. São Paulo: Cortez, 2015.

GOMES, R. Análise e interpretação de dados de pesquisa qualitativa. In: MINAYO, M. C. S. (Org.). Pesquisa social: teoria, método e criatividade. 28. ed. Petrópolis, RJ: Vozes, 2009. p. 79-108.

IMBERNON, F. Formação docente e profissional: formar-se para a mudança e a incerteza. Tradução Silvana Cobucci Leite. 9. ed. São Paulo: Cortez, 2011.

LÜDKE, M.; ANDRÉ, M. E. D. A. Pesquisa em Educação: abordagens qualitativas. São Paulo: EPU, 1986.

MARSIGLIA, A. C. G.; MARTINS, L. M. Contribuições da pedagogia histórico-crítica para a formação de professores. Germinal: Marxismo e Educação em Debate, Salvador, v. 5, n. 2, p. 97-105, dez. 2013. DOI: http://dx.doi.org/10.9771/gmed.v5i2.9702

MILANESI, I. Estágio supervisionado: concepções e práticas em ambientes escolares.

Educar em Revista. Curitiba, n. 46, p. 209-227, out./dez. 2012. DOI:

https://doi.org/10.1590/S0104-40602012000400015

PIMENTA, S. G. O estágio na formação de professores: unidade teoria e prática. 11. ed. São Paulo: Cortez, 2012.

PIMENTA, S. G.; LIMA, M. S. L. Estágio e docência. 8. Ed. São Paulo: Cortez, 2017. 
SAVIANI, D. Sobre a natureza e especificidade da educação. Germinal: Marxismo e Educação em Debate. Salvador, v. 7, n. 1, p. 97-105, dez. 2015. DOI:

http://dx.doi.org/10.9771/gmed.v7i1.13575

SILVERIO, L. E. R. As práticas pedagógicas e os saberes da docência na formação acadêmica-profissional em Ciências Biológicas. Orientadora: Sylvia Regina Pedrosa Maestrelli. 485 f. Tese (Doutorado em Educação Científica e Tecnológica) - Universidade Federal de Santa Catarina, Florianópolis, 2014.

SCHÖN, D. A. Educando o profissional reflexivo: um novo design para o ensino e a aprendizagem. Trad. Roberto Cataldo Costa. Porto Alegre: Artmed, 2000. 256 p.

TARDIF, M. Saberes docentes e formação profissional. 17. ed. Petrópolis: Vozes, 2014.

UNIVERSIDADE ESTADUAL DO CEARÁ. Plano de Desenvolvimento Institucional. Fortaleza, 2017. 120 p. Disponível em: http:/www.uece.br/institucional/pdi/. Acesso em: 5 jun. 2020.

VEIGA, I. P. A. Formação de professores para a Educação superior e a diversidade da docência. Revista Diálogo Educacional, Curitiba, v. 14, n. 42, p. 327-342, maio/ago. 2014. DOI: http://dx.doi.org/10.7213/dialogo.educ.14.042.DS01

YIN, R. K. Estudo de caso: planejamento e métodos. 4. ed. Porto Alegre: Bookman; 2010.

\section{Como referenciar este artigo}

MACIEL, A. O.; NUNES, A. I. B. L.; PONTES JUNIOR, J. A. F. Estágio Supervisionado e Residência Pedagógica: possibilidades para formação docente crítica. Revista IberoAmericana de Estudos em Educação, Araraquara, v. 15, n. esp. 3, p. 2223-2239, nov. 2020. e-ISSN: 1982-5587. DOI: https://doi.org/10.21723/riaee.v15iesp3.14428

Submetido em: 20/07/2020

Revisões requeridas em: $30 / 08 / 2020$

Aprovado em: 29/09/2020

Publicado em: 30/10/2020 